Int. J. Electrochem. Sci., 11 (2016) 9762 - 9775

\title{
Inkjet Catalyst Printing and Electroless Ni-P Deposition for Fabrication of WWAN Antenna on PC/ABS Substrate
}

\author{
Yan-Yu Nian ${ }^{1}$, Shu-Chuan Chen ${ }^{2}$, Meng-JeyYouh ${ }^{3}$, Chang-Pin Chang ${ }^{3, *}$, Zhi-Yu Luo , \\ Ming-Der Ger, \\ ${ }^{1}$ School of Defense Science, Chung Cheng Institute of Technology, National Defense University, \\ Taiwan 335, ROC \\ ${ }^{2}$ Department of Electrical and Electronic Engineering, Chung Cheng Institute of Technology, National \\ Defense University, Taiwan 335, ROC \\ ${ }^{3}$ Department of Information Technology, Hsing Wu University, Taiwan244, ROC \\ ${ }^{4}$ Department of Chemical \& Materials Engineering, Chung Cheng Institute of Technology, National \\ Defense University, Taiwan 335, ROC \\ *E-mail: cpchang1@ ndu.edu.tw(C.-P. Chang), mingderger@gmail.com (M.-D. Ger)
}

doi: $10.20964 / 2016.11 .03$

Received: 26 July 2016 / Accepted: 30 August 2016 / Published: 10 October 2016

In this study, a method to fabricate WWAN antenna on a PC/ABS alloy substrate is described. This method involves inkjet printing of a thermo-sensitive St-co-NIPAAm/Pd nanoparticle-based ink on PC/ABS substrate to create the catalytic site, onto which nickel is subsequently deposited by an electroless plating method, to obtain the desired metal pattern. Prior to electroless plating, pretreatments of PC/ABS by swelling and etching are utilized to improve the adhesion strength between PC/ABS substrate and elctroless Ni-P coating. After the optimal swelling and etching treatments, the surface contact angle of PC/ABS decreases from $92^{\circ}$ to $22^{\circ}$ and the surface average roughness $(\mathrm{Ra})$ increases from 329 to $2232 \mathrm{~nm}$. The adhesion strength and corrosion resistance the electroless Ni-P deposit increases as the $\mathrm{pH}$ value of the plating bath decreases. The maximum adhesion strength, about $2.3 \mathrm{MPa}$, is obtained at a bath $\mathrm{pH}$ of 5. Our result also demonstrates that this procedure is successfully applied for fabricating WWAN antenna with desired resonant frequencies.

Keywords: Inkjet printing; Electrolessplating; Metal patterns; Antenna; PC/ABS

\section{$\underline{\text { FULL TEXT }}$}

C) 2016 The Authors. Published by ESG (www.electrochemsci.org). This article is an open access article distributed under the terms and conditions of the Creative Commons Attribution license (http://creativecommons.org/licenses/by/4.0/). 